\title{
Globalisation of information systems in Australian organisations
}

\author{
P. R. Cerotti, RMIT Business Higher Education \\ 235 Bourke Street, Melbourne 3000, Australia \\ Telephone: 61039660 5785, Fax:610396605850 \\ E-mail paulc@metro.bf.rmit.edu.au \\ J. Clifton, RMIT Business Higher Education, \\ 235 Bourke Stree,t Melbourne 3000, Australia \\ Telephone: 61039660 5786, Fax:610396605850 \\ E-mail judithc@metro.bf.rmit.edu.au
}

\section{Introduction}

\section{Extended Abstract}

Global communications technology offers those organisations that embrace it many strategic advantages in conducting business overseas; despite this however, it has not been a technology that Australian organisations have rushed to implement.

It was during the Eighties that discussions about the globalisation of business began; new markets were needed in order to sustain growth and to combat the number of foreign organisations entering the Australian marketplace and encroaching on existing business.

This paper investigates several Australian organisations and looks at their usage of global communications technology; the organisations chosen are a mix of those that are Australian owned and those that have their headquarters overseas. Some of the organisations have been exporting their products or services for a number of years, whilst others are new to business operations on a global scale.

The number of organisations researched is probably too small to provide a definite result. However, there does seem to be a clear indication that global communications is a technology that all the Australian organisations (included in the research) have investigated and have then proceeded to implement. The proviso is of course that it does offer some definable form of competitive advantage when conducting business overseas.

This paper describes an investigation into the use of global communications technology by Australian organisations paying particular attention to the following:

1. The long term information and management strategies organisations adopted when implementing global communications technology, 
2. How information systems technology has been used to enhance the profitability of the organisations and also to contribute to the further expansion of the company's operations globally.

3. An evaluation of the role of global communications technology in sustaining a global competitive advantage for the organisation.

\section{The Research Approach}

A questionnaire was developed for use when conducting interviews with employees, holding a position in Management, in the selected organisations.

Six Australian organisations were selected for the research project; the organisations were selected for the following reasons:

- they were known to be conducting business on a global basis

- they had recently begun conducting business on a global basis,

- they were companies with their head offices overseas.

These organisations selected are listed below:

- BHP

- BP Oil

- Ansett Airlines

- Mattel Australia

- Carlton and United Breweries

- Knowledge Engineering Pty Ltd

\author{
Australia's Largest Company \\ Multinational Oil Company \\ Major Australian Airline \\ Multinational Toy Manufacturer \\ Australia's Largest Brewer \\ I. T. Consultancy
}

\section{Conclusion}

The relatively small number of organisations questioned prevents a definite conclusion being drawn, however, several similarities emerged from the answers provided.

The globalisation of business has become an important management strategy but only for those organisations who believe that some form of competitive advantage can be derived from such technologies. Most organisations began using global telecommunications in a rather ad hoc fashion however, management now play a more important role in deciding the future use of such technologies.

Those organisations that have been using global communications to conduct business for at least a few years state quite conclusively that being well informed of business opportunities worldwide does enhance profitability: the enhancement is derived mainly from cost savings. Several organisations believe that profitability was enhanced by global communications enabling them to be informed about business opportunities before their competitors but this advantage disappeared as soon as competitors improved their own global communications.

Manufacturing organisations indicate that the enhancement of their profitability is derived by being in touch with all markets and distributors around the world which enables them to optimise their production.

The competitive advantage gained by organisations is, again mainly through being better informed; as soon as information is available it can be acted upon which means that, despite the distances involved in competing for business in Europe, it can be accomplished much more easily than before. 